\title{
Phenotypic Characteristics as Predictors of Phytosterols in Mature Cycas micronesica Seeds
}

\author{
Thomas E. Marler ${ }^{1}$ \\ College of Natural and Applied Sciences, UOG Station, University of Guam, \\ Mangilao, Guam 96923
}

\section{Christopher A. Shaw \\ University of British Columbia, Departments of Ophthalmology and Medical Science, Vancouver, British Columbia, Canada}

Additional index words. accumulation, cycads, Guam, phenotypic plasticity, size, sterol, steryl glucoside

\begin{abstract}
The relationship between mature Cycas micronesica K.D. Hill seed sterol concentration and content and plant or seed phenotypic characteristics was established by multiple regression. Combined models were significant for free but not glycosylated sterols. Reduced models revealed leaf number as the only significant predictor. Free and glycosylated sterol concentrations were unaffected throughout the range of several predictors: tree height $(1.7$ to $5.8 \mathrm{~m})$, seed fresh weight (48 to $120 \mathrm{~g})$, seed load (one to 76 seeds per plant), and estimated tree age ( 32 to 110 years). The free and glycosylated sterol phenotypes were also not dependent on the presence/absence of developed embryos in mature seeds. The significant response to leaf number was subtle with an increase of 43 leaves associated with a $0.1-\mathrm{mg}$ increase in free sterol per gram seed fresh weight. This is the first report for any cycad that discusses reproductive or physiological traits in the context of allometric relations. Results indicate a highly constrained phenotypic plasticity of Cycas gametophyte sterol and steryl glucoside concentration and seed content in relation to whole plant and organ size variation.
\end{abstract}

Contemporary cycads form a primitive plant group, and research on this group may yield increased understanding of many aspects of plant biology (Brenner et al., 2003). The study of cycad taxonomy has received recent attention, and the result is a description of roughly 300 species (Hill et al., 2007). In contrast, the study of cycad horticulture and physiology has been neglected, although more practical research may shed light on reasons why this plant group has persisted throughout hundreds of millions of years (Norstog and Nicholls, 1997). Furthermore, we have suggested more cycad taxa would become prevalent in the international cycad horticulture trade as a result of more practical research (Marler et al., 2007b).

Guam's native cycad taxa, Cycas micronesica K.D. Hill, provides a striking specimen plant in the urban landscape. Louis de Freycinet led a French scientific expedition

Received for publication 6 Mar. 2009. Accepted for publication 6 Mar. 2009.

Support provided by USDA CSREES (Project No. 2003-05495) to TEM and U.S. Army Medical and Materiel Command (DAMD17-02-1-0678), NSERC Canada, and Scottish Rite Charitable Foundation of Canada to CAS.

We thank V. Lee, D. Kwok, and N. Dongol for laboratory and field technical assistance. We thank George Fernandez, UNR Center for Research Design and Analysis, for statistical analyses.

${ }^{1}$ To whom reprint requests should be addressed; e-mail tmarler@uguam.uog.edu. on Guam for several months in 1819, and his records indicate that this taxa was among the most commonly planted crop plants in the homesteads of that era (Barratt, 2003). Additionally, phenology of the species controlled much of the scheduling in Guam's early 19th century agricultural calendar. Until recently, its contemporary use in the urban forest was secondary to that of the exotic Cycas revoluta Thunb. However, both species have been decimated from the horticultural scene as a result of the 2003 invasion of the cycadspecific scale Aulacaspis yasumatsui Takagi. This arthropod invasion positioned C. micronesica on the IUCN Red List only 3 years after it occurred (Marler et al., 2006a). For this and other threatened cycad taxa, increased horticultural research may improve the role of horticulture in conservation efforts.

Cycads are slow-growing, dioecious, longlived perennial plants. The Guam taxa is an arborescent species with stems to $6 \mathrm{~m}$ in the sites we have studied. Most female plants are monopodial, and one pseudocone is produced at a time. Ovule and ultimate seed number per pseudocone are highly heterogeneous, and up to 100 or more seeds is common. Seed maturation requires 20 to 24 months, but viable seeds can be harvested from plants as early as 12 months with postharvest embryo development. All cycads are characterized by an abundance of secondary compounds (Marler et al., 2005a). Some cycad compounds are toxins, and the study of these toxins may improve our understanding of health issues in relation to the myriad plant secondary compounds to which humans are exposed (Shaw et al., 2007).

We have been studying the physiology of $C$. micronesica in relation to a group of sterols and their derived glucosides because of the various issues discussed here. We have chosen these compounds because of the demonstrated epidemiological links between cycad seed consumption on Guam and amyotrophic lateral sclerosis-parkinsonism dementia complex (Borenstein et al., 2007; Whiting, 1963). Natural sterols and steryl glucosides extracted from cycad megagametophyte tissue (Fig. 1) are among the list of cycad compounds that have been studied in relation to toxicity, and they have proven to be the most neurotoxic compounds in various mammalian species (Kim et al., 2008; McDowell et al., 2007; Shaw et al., 2007; Tabata et al., 2008; Valentino et al., 2006). We have determined that spatial variation of concentration or content of these compounds in the cycad seed is strongest among plant locations and within seed tissues, moderate among plants within a location, and least among same-aged seeds within a plant (Marler et al., 2005b, 2007a). Concentration of these compounds is greatest in young seeds, declines linearly after $\log$ transformation of both axes as seeds increase in age while attached to plants (Marler et al., 2006b), but remains stable in detached seeds during extended storage (Marler et al., 2007b). Bioaccumulation of these compounds in megagametophytes is linear throughout seed ontogeny, and the glucosides accumulate more rapidly than the free sterols (Marler and Shaw, 2009).

Phenotypic plasticity of various traits is a critical aspect of plant physiology (e.g., van Kleunen and Fischer, 2007), yet we are aware of no studies that have determined the magnitude of phenotypic plasticity of any cycad compound in relation to plant or environmental factors. Thus, our recent focus has been to determine the magnitude of biosynthetic and

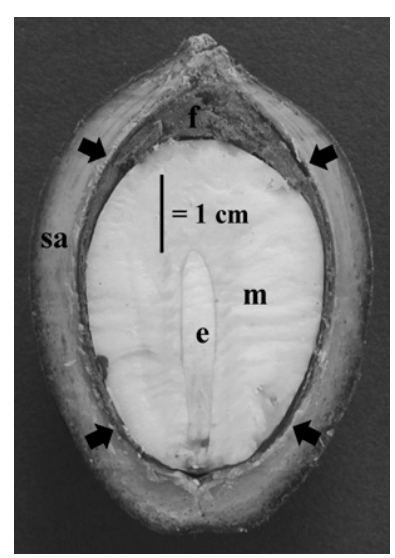

Fig. 1. Longitudinal section of typical 22-monthold Cycas micronesica seed with fully developed embryo. $\mathrm{e}=$ embryo; $\mathrm{f}=$ flotation tissue; $\mathrm{m}=$ megagametophyte; $\mathrm{sa}=$ sarcotesta . The arrows point to sclerotesta. 
allocational plasticity of the sterols and steryl glucosides in C. micronesica.

The aims of this study were to determine the association of several allometric factors with mature seed sterol and steryl glucoside concentrations and contents. The study of cycad gametophyte development may illuminate our understanding of evolution of the analogous angiosperm endosperm (Brenner et al., 2003), so our results may have broad implications within a range of disciplines. The specific phenotypic question we asked was, does concentration and total content of free and glycosylated sterols in seed megagametophytes of $C$. micronesica correlate with (1) somatic tissue size, seed load per plant, and the ratio of somatic tissue size to seed load, (2) mature seed size, or (3) embryo size in mature seeds?

\section{Materials and Methods}

The study site was located in northwest Guam, centered at long. $13^{\circ} 38^{\prime} 43^{\prime \prime} \mathrm{N}$, lat. $144^{\circ} 5130^{\prime \prime}$ E. Site characteristics were described in Marler et al. (2007a; Dededo 1 site). The site is located on the northwest coast of Guam with well-drained limestone soils (Clayey-skeletal, gibbsitic, nonacid, isohyperthermic Lithic Ustorthents; Young, 1988). Cycas micronesica plants were tagged and dated to record emergence of reproductive events during early 2003 . Trees that bore 22-month-old mature seeds in Feb. 2005 were used to study source-sink relations.

Study 1: Somatic tissue size and megagametophyte sterols. Seeds from each of 90 plants were harvested for this study. Eight seeds were harvested for each plant with at least eight seeds, and all seeds were harvested from plants with less than eight seeds. For plants with more than eight seeds, we counted the total number of seeds in the reproductive event as a measure of the plant's reproductive effort. We counted the number of leaves and estimated stem volume by multiplying stem height (from ground to apex cataphylls) and basal area as somatic determinants of seed sterol concentrations and contents. This approach overestimated stem volume (homogeneously among all trees) because we used the basal area rather than an average stem cross-sectional area.

Seeds were transported to the University of Guam for processing. Gametophyte tissue was removed and frozen then stored at $-40{ }^{\circ} \mathrm{C}$ until we had time to process the samples. Tissue was lyophilized and the dry weight of each seed was measured. The free sterols [stigmasterol (SS) and $\beta$-sitosterol (BSS)] and derived steryl glucosides [stigmasterol $\beta$-D-glucoside (SG) and $\beta$-sitosterol $\beta$-D-glucoside (BSSG)] were quantified as described by Marler et al. (2005b) as one composite sample for each plant. We focused on these sterols because they are the largest component of the sterol profile. The sum of SS and BSS provided one measure of concentration of these major free sterols, and the sum of SG and BSSG provided one measure of the concentration of their derived gluco- sides. Then total accumulation of the two free sterols and their glucosides was calculated from seed dry weight to estimate content per seed.

Study 2: Seed size and megagametophyte sterols. Seeds for this study were harvested at a uniform age of 22 months in Feb. 2005. We selected five productive trees 2 to $3 \mathrm{~m}$ in height and supported by a similar number of leaves and bearing a similar number of seeds for this study. From these, we selected 96 seeds that represented the range in size of all observations. Fresh weight of each seed was recorded and used as the independent variable. Gametophyte tissue was stored then lyophilized, weighed, and processed as described in Study 1.

Study 3: Embryo growth and megagametophyte sterols. We examined harvested seeds from the batch of seeds not used for Study 2 to identify seeds with complete embryo development versus seeds devoid of developed embryos. This is an unambiguous procedure using longitudinally sectioned gametophytes because mature embryos exceed $2 \mathrm{~cm}$ in length (Fig. 1). We selected 33 mature seeds and 33 seeds without fully developed embryos. Gametophyte tissue was stored, processed, and analyzed as in Study 1.

Statistical analysis. Study 1 data were subjected to a multiple linear regression model using a SAS macro application REGDIAG (Fernandez, 2002). First, we defined concentration of free sterols and derived steryl glucosides as response variables and the attributes seed number, leaf number, stem height, and stem volume were treated as predictors. Then we estimated the cumulative seed content for free sterols and steryl glucosides in a reproductive event by multiplying each plant's number of seeds by an average dry weight of seed gametophyte tissue from a sample of 100 random seeds. We used the multiple regression procedure with cumulative content of gametophyte free sterol and steryl glucoside as response variables and leaf number, stem height, and stem volume as predictors. Lastly, we determined the number of leaves supporting each seed using the ratio seed number/leaf number and then determined the general ratio of seeds that had access to stored stem resources as seed number/stem volume. These two measures of general size of somatic tissue relative to reproductive tissue were treated as predictors in the multivariate regression model with concentration of free sterols and steryl glucosides treated as response variables. Before examining the multiple linear regression model results, checks for multicollinearity, departure from homogeneity of variance, and significant heteroscedasticity were tested. None of the violations were severe. For Study 2 , we calculated sterol content per seed by multiplying gametophyte dry weight by sample concentration. We used the REG procedure (SAS software version 12.3; SAS Institute, Cary, NC) to determine the association of seed size with sterol and steryl glucoside concentration and cumulative content per seed. Because both sterols and steryl glucosides exhibited a linear association with seed size, we tested slope homogeneity between the two populations using the GLM procedure. For Study 3, we used the analysis of variance procedure to determine differences between seeds with and without fully developed embryos.

\section{Results}

Somatic tissue size and megagametophyte sterols. The overall multiple linear regression with gametophyte sterol concentration as the response variable and seed number, leaf number, stem height, and stem volume designated as predictors was significant $(P \leq$ 0.0133 ). Among the predictor variables, only leaf number was significant $(P \leq 0.0269$; Table 1). The reduced regression model (Fig. $2 \mathrm{~A}$; slope $\left.=0.0023 ; P \leq 0.0024 ; R^{2}=0.10\right)$ indicated that each addition of $\approx 43$ leaves per plant was associated with a $0.1-\mathrm{mg} \cdot \mathrm{g}^{-1}$ increase in sterol concentration. In contrast, seed number, leaf number, stem height, and stem volume were not significant predictors of steryl glucoside concentration in gametophyte tissue (multiple linear regression model, $P \leq 0.2362$ ).

Table 1. Full multiple linear regression model parameter estimates for Cycas micronesica seed gametophyte free sterol concentration with predictors seed number, leaf number, stem height, and stem volume.

\begin{tabular}{lcrcc}
\hline Variable & df & $\begin{array}{c}\text { Parameter } \\
\text { estimate }\end{array}$ & SE & $P$ \\
\hline Intercept & 1 & 0.49689 & 0.13679 & 0.0005 \\
$\begin{array}{l}\text { Seed } \\
\quad \text { number }\end{array}$ & 1 & -0.00009 & 0.00097 & 0.9278 \\
$\begin{array}{c}\text { Leaf } \\
\text { number }\end{array}$ & 1 & 0.00241 & 0.00107 & 0.0269 \\
$\begin{array}{c}\text { Stem } \\
\quad \text { height }\end{array}$ & 1 & -0.00073 & 0.00048 & 0.1369 \\
$\begin{array}{c}\text { Stem } \\
\text { volume }\end{array}$ & 1 & 0.10801 & 0.19567 & 0.5824 \\
\hline
\end{tabular}

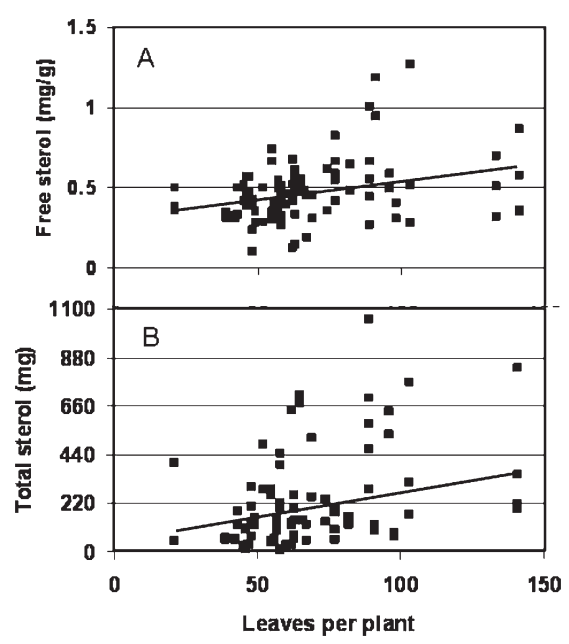

Fig. 2. Free sterol concentration (A) and total free sterol content in entire reproductive event (B) for Cycas micronesica megagametophyte tissue as influenced by number of leaves per plant. 
Multiple linear regression revealed that seed number/leaf number or seed number/ stem volume were not significant predictors of sterol $(P \leq 0.3482)$ and steryl glucoside $(P \leq 0.2880)$ concentration. Therefore, gametophyte sterols were independent of the relative size of reproductive tissue as a function of somatic tissue size available to support those reproductive efforts.

Overall multiple linear regression revealed a significant relationship between cumulative free sterol gametophyte content within the reproductive event and leaf number, stem height, and stem volume as predictors $(P \leq 0.0259)$. As for sterol concentration, leaf number was the only significant predictor (Table 2). The reduced regression model (Fig. 2B; slope $=2.342 ; P \leq 0.0053$; $R^{2}=0.08$ ) revealed that each addition of $\approx 4$ leaves of a $C$. micronesica plant was associated with addition of $10 \mathrm{mg}$ of total free sterol in the entire reproductive event. Steryl glucoside content of gametophyte tissue was not influenced by leaf number, stem height, or stem volume (multiple linear regression model, $P \leq 0.4333)$.

Seed size and megagametophyte sterols. Free sterol concentration of 22-month-old seed gametophytes was $0.48 \pm 0.19 \mathrm{mg} \cdot \mathrm{g}^{-1}$ (mean $\pm \mathrm{SD}$ ) and was not influenced by seed weight $(P \leq 0.5079)$. However, the cumulative gametophyte free sterol content increased with seed weight (Fig. 3; slope = $\left.0.133 ; P \leq 0.0001 ; R^{2}=0.25\right)$. Steryl glucoside concentration was independent of seed weight with a mean of $0.67 \pm 0.41 \mathrm{mg} \cdot \mathrm{g}^{-1}$. Gametophyte steryl glucoside content increased linearly with seed weight (slope

Table 2. Full multiple linear regression model parameter estimates for total pool of free sterols in Cycas micronesica seed gametophyte tissue with predictors leaf number, stem height, and stem volume.

\begin{tabular}{lcccc}
\hline Variable & df & $\begin{array}{c}\text { Parameter } \\
\text { estimate }\end{array}$ & SE & $P$ \\
\hline Intercept & 1 & 73.1331 & 151.672 & 0.6309 \\
Leaf & 1 & 3.07414 & 1.16667 & 0.0100 \\
$\quad$ number & & & & \\
$\begin{array}{l}\text { Stem } \\
\quad \text { height }\end{array}$ & 1 & -0.12922 & 0.53775 & 0.8107 \\
$\begin{array}{l}\text { Stem } \\
\quad \text { volume }\end{array}$ & 1 & -112.549 & 217.340 & 0.6059 \\
\hline
\end{tabular}

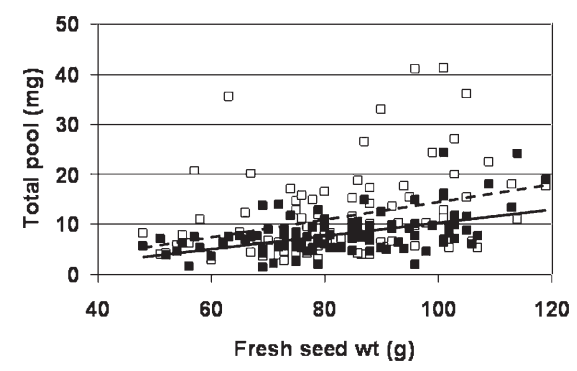

Fig. 3. Total free sterol (closed squares, solid line) and steryl glucoside (open squares, dashed line) content in Cycas micronesica seeds as influenced by seed fresh weight. $\left.=0.179 ; P \leq 0.0007 ; R^{2}=0.12\right)$. The test for homogeneity of slopes was not significant $(P \leq 0.4513)$, indicating free sterol and steryl glucoside contents increased similarly with seed weight. The ratio of free sterols to steryl glucosides was 1:1.4 and was not influenced by seed size.

Embryo growth and megagametophyte sterols. Embryo length did not influence free sterol $(P \leq 0.1201)$ or steryl glucoside $(P \leq$ 0.2916 ) concentration in gametophyte tissue of 22-month-old seeds. Additionally, embryo development was not a determinant of total seed content of free sterols $(P \leq 0.1453)$ or steryl glucosides $(P \leq 0.3676)$.

\section{Discussion}

Plant size. The lack of attention to plant size in physiology studies has the potential to introduce ambiguities in interpretation of results (Zotz, 2000). We are not aware of any other report for a cycad that addresses the relationship between plant size and a physiological trait. The relative size of a plant influences resource relations (Berntson and Wayne, 2000). Increased plant size and the accompanying increased acquisition of resources do not necessarily lead to greater availability of these resources and their products for reproductive efforts because the proportion of resource-acquiring tissue to whole plant biomass decreases as plants become larger (e.g., Cannell and Dewar, 1994). Furthermore, the persistent live pith and cortex of a cycad stem are comprised of starch-rich parenchyma (Fisher and Marler, 2006; Norstog and Nicholls, 1997), and this live stem tissue may uniquely impact source-sink relations.

In this study, we predicted a positive correlation between stem size and allocation of sterols and steryl glucosides to seed gametophyte tissue. The results were inconsistent with this prediction. Our range in $C$. micronesica stem size was considerable for this slow-growing species (e.g., 1.7 to $5.8 \mathrm{~m}$ in height), so attributing the lack of influence on seed sterol and steryl glucoside concentration to sampling bias was unlikely. The 675 -fold difference between the minimum and maximum value of the nonsignificantderived predictor seed number/stem volume affirms the conclusion that stem size did not influence gametophyte sterol relations. One explanation is that sterol and steryl glucoside biosynthesis and/or import in Cycas seeds is uncoupled from reliance on the abundant nonstructural stem resources. Alternatively, the quantity of stem resources accessed to support seed sterol metabolism may be fixed rather than scaled with available volume of stem parenchyma. Finally, stem tissue may act as a competing sink rather than a source of substrates for seed sterol relations.

The scant literature on plant size in relation to secondary chemistry is typically presented indirectly by characterizing a range in plant age. The inferences to size are generally valid because plant size normally increases with each developmental stage during developmental ontogeny. Hirsh and
Marler (2002) reported a stem height increment for $C$. micronesica of $\approx 5.25 \mathrm{~cm}$ per year. Using this as a tenable average for comparative purposes, our survey was represented by plants from 32 to 110 years old. Therefore, mature seed gametophyte sterol and steryl glucoside concentration and accumulation were similar among plants that spanned many decades in estimated age.

This literature based on plant age does not directly illuminate our discussion because the causal influences of ontogenetic stage changes and heterogeneous tissue age that are typical of the sampling methods cannot be separated from the direct influence of size relations. Moreover, these studies have reported highly contrasting results. For example, concentration of six secondary compounds increased as Hypericum perforatum L. plants increased in age from preflowering through mature fruiting stages, but rutin concentration decreased concomitantly in the same tissue samples (Cirak et al., 2007). Similarly, sterol concentration in shoots was erratic over a 16-week growth period for Glycine $\max (\mathrm{L}$.) Merr. and a 12-week growth period for Cucurbita maxima Duchesne (Fenner et al., 1986). Concentration varied more than fivefold for Glycine and threefold for Cucurtiba over the growth period that encompassed the young seedling stage through plant senescence. Donaldson et al. (2006) reported on age-related changes in Populus tremuloides Michx. leaf chemistry with tree age up to 25 years old. This age range was roughly onethird of our age range, yet they discussed several developmental shifts in chemistry, including a sharp decline in phenolic glycosides as tree age increased.

Heupel et al. (1986) provided the only sterol report we have found that ensured the use of a homogeneous tissue age for accurate sampling across a range in plant age. They studied sterol concentrations of mature Sorghum bicolor (L.) Moench leaf tissue over a 66-d growth period. Still, the influence of ontogenetic stage changes cannot be separated from the influence of inferred increase in plant size. Leaf sterol concentration was high at Day 7, declined until Day 34, increased until Day 48, then declined again thereafter. Concentration varied approximately sevenfold over their growth period.

Two reports have mentioned the influence of cycad plant age on leaf chemistry. Charlton et al. (1992) found no difference in concentration of leaf 2-amino-3-(methylamino)-propanoic acid content of "young" and "mature" Cycas circinalis L. plants. Yagi and Tadera (1987) found no difference in content of leaf cycasin and macrozamin of "seedling" and reproductive C. revoluta plants.

Leaf number. Cycas leaves are large and expensive to construct in terms of plant carbon economy (Marler, 2004). After mature leaf size has been attained, their contribution as a carbon source extends for years (Marler, 2007). Therefore, a plant that is supported by a larger number of these long-lived leaves has potential access to considerable carbon for 
secondary metabolism. We predicted the number of leaves on a $C$. micronesica plant would be positively correlated with sterol and steryl glucoside relations in seeds. Results were consistent with this prediction for sterols, but not for steryl glucosides.

One intriguing contrast in our results is that leaf number positively influenced sterol concentration and accumulation but relative stem size did not. This may indicate that the biosynthetic steps in sterol synthesis in developing Cycas seeds may depend on recently assimilated carbon but not on stem-stored nonstructural carbon substrates that are suitable donors for sterol synthesis. A second interesting contrast was that free sterol accumulation in seeds was positively influenced by leaf number but steryl glucoside accumulation was not. This may indicate indirectly that steryl glucoside synthesis is isolated from reliance on newly available primary sugars either physically by compartmentalization or biochemically by the additional conjugation steps required to achieve the derived glucosides.

The positive correlation of leaf number and total sterol content in a reproductive event was partly mediated by the small increase in concentration with increased leaf number. However, the major driver of this association was the greater seed biomass associated with increased leaf number.

Seed size. The size of a reproductive structure may be correlated with concentration and accumulation of secondary compounds. For example, the size of pome fruits was positively correlated with gibberellin concentration and negatively correlated with abscisic acid and calcium concentrations (Schröder and Link, 2002; Zhang et al., 2007). We predicted a significant correlation of Cycas seed size with sterol or steryl glucoside concentration because the natural size range of $C$. micronesica seeds is substantial; sterol, gibberellin, and abscisic acid share precursors in the same biosynthetic pathway (Goodwin and Mercer, 1983); and the metabolic relationship among these metabolites is integrated (Fraser et al., 1995). Our results did not support this prediction. Our range in mature seed size of 48 to $120 \mathrm{~g}$ fresh weight was considerable and accurately encompassed the range in seed size typical for this species. Thus, we do not believe the lack of correlation between seed size and concentration was the result of insufficient range in seed size in our study.

Fecundity. Fruit chemistry is among the traits that are affected by relative crop load (Childers, 1995). For example, Stopar et al. (2002) reported a decrease in fruit polyphenol concentration with increased apple (Malux $\times$ domestica Borkh.) fruit set, and Spayd et al. (1986) reported a decrease in fruit acid, anthocyanin, and sugar concentrations with increased sweet cherry (Prunus avium L.) fruit set. These reports led us to previously predict (Marler et al., 2005a) that the natural variation in seed number per reproductive event would be correlated with the range in seed chemistry in cycad plants. We have now determined that $C$. micronesica seed gametophyte sterol and steryl glucoside concentrations are not correlated with seed set within a robust range of one to 76 seeds per plant.

Embryo and sterol profile relations. The large cycad megagametophyte develops before embryo development, and embryo growth into the gametophyte likely involves enzymatic digestion of the haploid tissue to nourish embryo development (Brough and Taylor, 1940). Disparity in timing of embryo maturation is a common characteristic among Cycas seeds of the same age and size (Dehgan and Schutzman, 1989). Horbowicz and Obendorf (1992) noted a shift in sterol and fatty acid relations associated with the period of embryo growth during Fagopyrum esculentum Moench seed development. Therefore, we predicted a disparity in content and/or profile of the sterol compounds for Cycas seeds with or without mature embryo development. In contrast, concentration and total content of the compounds was not associated with the presence or absence of a developed embryo in mature seeds in the present study. The ratio of free/glucoside forms of the sterols was also unaffected by embryo development.

Sterols are architectural components of plant membranes and regulate fluidity and permeability (Schaller, 2003). Sterols (Schaller, 2004) and steryl glucosides (Kimura et al., 1975) may be involved in hormone relations. Sterols are involved in plant development and gene expression, and steryl glucosides may serve as carriers or donors of compounds for biosynthesis of structural or functional end products (Cantatore et al., 2000; He et al., 2003; Peng et al., 2002). Lengthy C. micronesica seed storage did not alter gametophyte concentration of these compounds (Marler et al., 2007b), which indicates their function may be realized later during embryo or seedling development. However, the lack of difference in sterol concentrations/contents within seeds with or without fully developed embryos reported here indicates the early gametophyte sterol and steryl glucoside pools are not metabolized to support embryo development during seed ontogeny. Hou et al. (1968) suggest steryl glucosides accumulate in seeds as storage forms of sterols. Our results support this suggestion, because glucoside content was $140 \%$ of free sterol content. Although seed weight was not correlated with concentration of sterols and steryl glucosides, it was positively correlated with their content (Fig. 3). These collective results indicate the free sterols may be of structural importance for seed integrity, and the glucosides may be of "nutritional" importance for deployment during germination and early seedling growth. Seedlings developing from larger seeds are therefore expected to have greater initial growth as a result of greater availability of these and other gametophyte resources.

Concluding remarks. Considering the essential nature of sterols in plant membranes, the lack of information on environmental factors that govern their phenotypic plasticity deserves our attention. Moreover, the importance of a full understanding of the physiology of sterols and steryl glucosides in horticultural plant relations is underscored by evidence that ingestion of the free sterols (Kim et al., 2008) and derived glucosides (Shaw et al., 2007; Tabata et al., 2008) in mammalian systems can be highly neurotoxic. Additionally, dietary intake of sterols is one candidate for genesis of degenerative accumulation of lipid-containing plaques on arterial walls (e.g., Sudhop and von Bergmann, 2004). Enigmatically, free sterols are also being advocated for use in human dietary products for treatment of benign prostatic hyperplasia, rheumatoid arthritis, and allergies (e.g., Oomah and Mazza, 1999) and for claimed cholesterol-lowering and anticancer properties (Bradford and Awad, 2007; Moreau et al., 2002). Continuing to clarify how sterol metabolism in horticultural crops relates to intrinsic and environmental factors known to influence plant secondary metabolism will benefit the medical and food sciences.

Overall, our results indicate that the concentration of sterols and steryl glucosides in gametophyte tissue of mature C. micronesica seeds is a highly stable trait. We have shown that free and glycosylated sterol concentration and total seed content were consistent throughout an extensive range in stem size, seed size, fecundity, and estimated plant age. These traits were also not influenced by the presence or absence of a fully developed embryo in same-aged seeds. Although seed sterol concentration exhibited a positive correlation with leaf number, the amplitude of plasticity was small because the addition of 43 leaves $(36 \%$ of the range in leaf number) was associated with a $0.1-\mathrm{mg} \cdot \mathrm{g}^{-1}$ increase in concentration. Phenotypic plasticity of Cycas seed sterols appears highly constrained, possibly to ensure a fixed adequate sterol and steryl glucoside supply in mature seed gametophytes regardless of abundant variation in developmental factors that affect the expression of secondary compounds in other spermatophyte species.

\section{Literature Cited}

Barratt, G. 2003. An account of the Corvette L'Uraine's sojourn at the Mariana Islands, 1819. Occasional Historical Papers No. 13. Saipan, Commonwealth of the Northern Mariana Islands, Division of Historic Preservation.

Berntson, G.M. and P.M. Wayne. 2000. Characterizing the size dependence of resource acquisition within crowded plant populations. Ecology 81:1072-1085

Borenstein, A.R., J.A. Mortimer, E. Schofield, Y. Wu, D.P. Salmon, A. Gamst, J. Olichney, L.J. Thal, L. Silbert, J. Kaye, U.L. Craig, G.D. Schellenberg, and D.R. Galasko. 2007. Cycad exposure and risk of dementia, MCI, and PDC in the Chamorro population of Guam. Neurology 68:1764-1771.

Bradford, P.G. and A.B. Awad. 2007. Phytosterols as anticancer compounds. Mol. Nutr. Food Res. 51:161-170.

Brenner, E.D., D.W. Stevenson, and R.W. Twigg. 2003. Cycads: Evolutionary innovations and 
the role of plant-derived neurotoxins. Trends Plant Sci. 8:446-452.

Brough, P. and M.H. Taylor. 1940. An investigation of the life cycle of Macrozamia spiralis Miq. Proc. Linn. Soc, New South Wales. 65: 494-524.

Cannell, M.G.R. and R.C. Dewar. 1994. Carbon allocation in trees: A review of concepts for modeling. Adv. Ecol. Res 24:59-104.

Cantatore, J.L., S.M. Murphy, and D.V. Lynch. 2000. Compartmentation and topology of glucosylceramide synthesis. Biochem. Soc. Trans. 28:748-750.

Charlton, T.S., A.M. Marini, S.P. Makey, K. Norstog, and M.W. Duncan. 1992. Quantification of the neurotoxin 2-amino-3-(methylamino)-propanoic acid (BMAA) in Cycadales. Phytochemistry 31:3429-3432.

Childers, N. 1995. Modern fruit science: Orchard and small fruit culture. Horticultural Publications, Gainesville, FL.

Cirak, C., J. Radusiěnë, B. Karabük, V. Janulis, and L. Ivanauskas. 2007. Variation of bioactive compounds in Hypericum perforatum growing in Turkey during its phenological cycle. J. Integr. Plant Biol. 49:615-620.

Dehgan, B. and B. Schutzman. 1989. Embryo development and germination of Cycas seeds. J. Amer. Soc. Hort. Sci. 114:125-129.

Donaldson, J.R., M.T. Stevens, H.R. Barnhill, and R.L. Lindroth. 2006. Age-related shifts in leaf chemistry of clonal aspen (Populus tremuloides). J. Chem. Ecol. 32:1415-1429.

Fenner, G.P., G.W. Patterson, and P.M. Koines. 1986. Sterol composition during the life cycle of the soybean and the squash. Lipids 21:4851.

Fernandez, G. 2002. Data mining using SAS Applications. CRC/Chapman-Hall, New York, NY.

Fisher, J.B. and T.E. Marler. 2006. Eccentric growth but no compression wood in a horizontal stem of Cycas micronesica (Cycadales). Intl. Assoc. Wood Anatomists J. 27:377-382.

Fraser, P.D., P. Hedden, D.T. Cooke, C.R. Bird, W. Schuch, and P.M. Bramley. 1995. The effect of reduced activity of phytoene synthase on isoprenoid levels in tomato pericarp during fruit development and ripening. Planta 196:321326.

Goodwin, T.W. and E.I. Mercer. 1983. Introduction to plant biochemistry. 2nd Ed. Pergamon Press, New York, NY.

He, J.-X., S. Fujiko, T.C. Li, S.G. Kang, H. Seto, S. Takatsuto, S. Yoshida, and J.-C. Jang. 2003. Sterols regulate development and gene expression in Arabidopsis. Plant Physiol. 131:12581269.

Heupel, R.C., Y. Sauvaire, P.H. Le, E.J. Parish, and W.D. Nes. 1986. Sterol composition and biosynthesis in sorghum: Importance to developmental regulation. Lipids 21:69-75.

Hill, K.D., D.W. Stevenson, and R. Osborne. 2007. The world list of cycads. Mem. N. Y. Bot. Gard. 97:454-483.

Hirsh, H. and T. Marler. 2002. Damage and recovery of Cycas micronesica after Typhoon Paka. Biotropica 34:598-602.
Horbowicz, M. and R.L. Obendorf. 1992. Changes in sterols and fatty acids of buckwheat endosperm and embryo during seed development. J. Agr. Food Chem. 40:745-750.

Hou, C.T., Y. Umemura, M. Nakamura, and S. Funahashi. 1968. Enzymatic synthesis of steryl glucoside by a particulate preparation from immature soybean seeds. J. Biochemistry 63:351-360.

Kim, H.-J., X. Fan, C. Gabbi, K. Yakimchuk, P. Parini, M. Warner, and J.-A. Gustafsson. 2008. Liver $X$ receptor $\beta(\mathrm{LXR} \beta)$ : A link between $\beta$-sitosterol and amyotrophic lateral sclerosisParkinson's dementia. Proc. Natl. Acad. Sci. USA 105:2094-2099.

Kimura, Y., A. Tietz, and S. Tamura. 1975. Stigmasteryl- $\beta$-D-glucoside as an auxin synergist. Planta 126:289-292.

Marler, T., J. Haynes, and A. Lindström. 2006a. Cycas micronesica. In: IUCN 2006 red list of threatened species. 20 Mar. 2009. <http://www. iucnredlist.org $>$.

Marler, T.E., V. Lee, J. Chung, and C.A. Shaw. 2006b. Steryl glucoside concentration declines with Cycas micronesica seed age. Funct. Plant Biol. 33:857-862

Marler, T.E. 2004. Leaf physiology of shadegrown Cycas micronesica leaves following removal of shade. Bot. Rev. 70:63-71.

Marler, T.E. 2007. Age influences photosynthetic capacity of Cycas micronesica leaves. Mem. New York Bot. Garden 97:193-203.

Marler, T.E., V. Lee, and C.A. Shaw. 2005a. Cycad toxins and neurological diseases in Guam: Defining theoretical and experimental standards for correlating human diseases with environmental toxins. HortScience 40:1598-1606.

Marler, T.E., V. Lee, and C.A. Shaw. 2005b. Spatial variation of steryl glucosides in Cycas micronesica plants: Within- and among-plant sampling procedures. HortScience 40:16071611.

Marler, T.E., V. Lee, and C.A. Shaw. 2007a. Habitat heterogeneity of Cycas micronesica seed chemistry in Guam's forest. Micronesica 39:297-314.

Marler, T.E., V. Lee, and C.A. Shaw. 2007b. Storage does not influence steryl glucoside concentrations in Cycas micronesica seeds. HortScience 42:626-628.

Marler, T.E. and C.A. Shaw. 2009. Free and glycosylated sterol bioaccumulation in developing Cycas micronesica seeds. Food Chem. 115:615-619.

McDowell, K.A., K.M. Valentino, N.V. Dugger, W.-B. Shen, S.M. Clark, M.M. Hadjimarkou, J.A. Mong, and P.J. Yarowsky. 2007. Parkinsonism in rats induced by consumption of cycad toxin. Soc. for Neuroscience Abstracts. Society for Neuroscience, Washington, DC.

Moreau, R., B. Whitaker, and K. Hicks. 2002. Phytosterols, phytostanols, and their conjugates in foods: Structural diversity, quantitative analysis, and health-promoting uses. Prog. Lipid Res. 41:457-500.

Norstog, K.J. and T.J. Nicholls. 1997. The biology of the cycads. Cornell Univ. Press, New York, NY.
Oomah, B.D. and G. Mazza. 1999. Health benefits of phytochemicals from selected Canadian crops. Trends Food Sci. Technol. 10:193-198.

Peng, L., Y. Kawagoe, P. Hogan, and D. Delmer. 2002. Sitosterol- $\beta$-glucoside as primer for cellulose synthesis in plants. Science 295:147150 .

Schaller, H. 2003. The role of sterols in plant growth and development. Prog. Lipid Res. 42:163-175.

Schaller, H. 2004. New aspects of sterol biosynthesis in growth and development of higher plants. Plant Physiol. Biochem. 42:465-476.

Schröder, M. and H. Link. 2002. Calcium content in apple fruits after thinning treatments in relation to crop load, fruit size and leaf area. Acta Hort. 594:541-545.

Shaw, C.A., J.M.B. Wilson, R. Cruz-Aguado, S. Singh, E.L. Hawkes, V. Lee, and T. Marler. 2007. Cycad-Induced neurodegeneration in a mouse model of ALS-PDC: Is the culprit really BMAA or is a novel toxin to blame? Mem. New York Bot. Garden 97:286-307.

Spayd, S.E., E.L. Proebsting, and L.D. Hayrynen. 1986. Influence of crop load and maturity on quality and susceptibility to bruising of 'Bing' sweet cherries. J. Amer. Soc. Hort. Sci. 111: 678-682.

Stopar, M., U. Bolcina, A. Vanco, and U. Vrhovsek. 2002. Lower crop load for cv. Jonagold apples (Malus $\times$ domestica Borkh.) increases polyphenol content and fruit quality. J. Agr. Food Chem. 50:1643-1646.

Sudhop, T. and K. von Bergmann. 2004. Sitosterolemia-A rare disease. Z. Kardiol. 93:921928.

Tabata, R.C., J.M.B. Wilson, P. Ly, P. Zwiegers, D. Kwok, J.M. Van Kampen, N. Cashman, and C.A. Shaw. 2008. Chronic exposure to dietary sterol glucosides is neurotoxic to motor neurons and induces and ALS-PDC phenotype. Neuromolecular Med. 10:24-39.

Valentino, K.M., N.V. Dugger, E. Peterson, J.M. Wilson, C.A. Shaw, and P.J. Yarowsky. 2006. Environmentally-induced parkinsonism in cycadfed rats. Soc. for Neuroscience Abstracts. Society for Neuroscience, Washington, DC.

van Kleunen, M. and M. Fischer. 2007. Progress in the detection of costs of phenotypic plasticity in plants. New Phytol. 176:727-730.

Whiting, M.G. 1963. Toxicity of cycads. Econ. Bot. 17:271-302.

Yagi, F. and K. Tadera. 1987. Azoxyglycoside contents in seeds of several cycad species and various parts of Japanese cycad. Agr. Biol. Chem. 51:1719-1721.

Young, F.J. 1988. Soil survey of territory of Guam. US Department of Agriculture Soil Conservation Service.

Zhang, C., K. Tanabe, M. Mori, and E. Sakuno. 2007. Biologically active gibberellins and abscisic acid in fruit of two later-maturing Japanese pear cultivars with contrasting fruit size. J. Amer. Soc. Hort. Sci. 132:452-458.

Zotz, G. 2000. Size-related intraspecific variability in physiological traits of vascular epiphytes and its importance for plant physiological ecology. Perspect. Plant Ecol. Evol. Syst. 3:19-28. 